SAE paper 2004-32-0009. Copyright @ 2004 SAE International. This paper is posted on this site with permission from SAE International, and is for viewing only. Further use or distribution of this paper is not permitted without permission from SAE" 


\title{
Numerical Visualization of Air Short-Circuiting in a Small Two-Stroke SI Engine
}

\author{
Guang Hong, A.N.F. Mack, F. Menolotto' ${ }^{1}$, C. S. Jamieson ${ }^{2}$, S. G. Main ${ }^{3}$ \\ University of Technology, Sydney (UTS)
}

Copyright $(2004$ SAE Intemational and Copyright $\odot 2004$ Society of Automotive Engineers of Japan, Inc.

\begin{abstract}
A 3-D CFD model for a small two-stroke SI engine has been developed using a commercial code. The model simulates the scavenging process from the exhaust port opening to closing. The fluid in this model is air only. RNG (re-normalized group) was adopted as the turbulence model. The moving piston was achieved using the deforming grid technique. Various methods for numerically visualizing the air short-circuited through the exhaust port were investigated. This paper reports the modified Janté method, particle spray and thermal images. Although the results are only qualitative identification of air short-circuiting, they show that all three methods have the potential to achieve quantitative identification of fresh charge short-circuiting.
\end{abstract}

\section{INTRODUCTION}

Traditional carbureted two-stroke engines are well known for their good power-to-volume ratio but also for their poor $\mathrm{HC}$ emission caused by the fresh fuel which is short-circuited through the exhaust port. In a two-stroke engine design or development, it is important to know when, how and how much the fresh charge is short circuited. Even in the case using fuel injection, the evaluation of the scavenging process still plays an important role in CFD simulation [7] as we always want to minimize the pumping loss and to trap the fresh air as much as possible. Work on simulation of the scavenging process before 1997 was reviewed by $Y u$ et. al. [7] and reported in $[3,5]$. With rapidly improved computing facilities, CFD models of the two stroke engine power cycle have become more attractive and useful to engine designers and researchers $[1,2,4,6]$. Most of the previous work was focused on modeling the fluid flow in the cylinder, including direct fuel injection. This paper reports work on visualizing the air short-circuiting which simulates the actual phenomenon of fuel short-circuiting in a small two-stroke engine.

\section{ENGINE MODELING}

THE ENGINE - The engine involved in this modeling is a two-stroke spark ignition engine which employs crank case compression and has blister style transfer ports. Figure 1 shows the basic engine configuration. The major engine specifications are provided in Table 1.

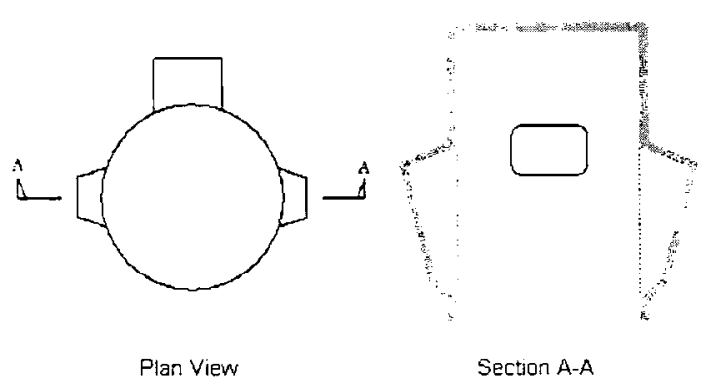

Figure 1 Basic engine configuration

Table 1 Engine specifications

\begin{tabular}{|l|l|}
\hline No. of cylinders & 1 \\
\hline Scavenging process & $\begin{array}{l}\text { Schnurle-loop } \\
\text { scavenging }\end{array}$ \\
\hline Bore $(\mathrm{mm})$ & 61.5 \\
\hline Stroke (mm) & 54 \\
\hline Displacement (cc) & 160 \\
\hline Exhaust port opening (ATDC) & $105.9^{0}$ \\
\hline Transfer port opening (ATDC) & $117.8^{0}$ \\
\hline Transfer port closing (ATDC) & $242.2^{0}$ \\
\hline Exhaust port closing (ATDC) & $254.1^{0}$ \\
\hline
\end{tabular}

${ }^{1}$ Currently employed by Vinidex, NSW, Australia.

${ }^{2}$ Currently employed by Defire, NSW, Australia.

${ }^{3}$ Currently employed ALSTOM Power, NSW, Australia 
COMPUTATIONAL MODELING - The CFD model for this small two-stroke engine was developed using CFDACE.

Mathematical model selection - Turbulence models provided by the code are divided into two groups: Reynolds Averaged Navier-Stoke simulations (RANS) and Large Eddy simulations (LES). RANS include standard $k-\varepsilon$ and RNG $k-\varepsilon$. Referring to other researcher's [1] and our previous experiences in CFD simulations, the RNG variation was employed in our simulation. The finite volume method was used to numerically compute the solutions.

The scavenging flow is a three-dimensional, unsteady, compressible and non-isothermal turbulent flow.

Engine geometry and mesh generation - The engine geometry includes the interior surface of the engine block, the bottom surface of the cylinder head, the piston crown, the transfer ports and the exhaust port.

Structured grids, because of their reliance on approximately rectangular domains, can be cumbersome and time consuming to construct. Some level of geometrical simplification or division is often required. On the other hand, unstructured grids can be more readily applied to complex geometries due to their ability to more easily generate grids within defined external surfaces. However, unstructured grids also require more memory and more computational time because of the need to store additional connectivity information.

Because of the relatively simple geometry of the small two-stroke engine to be modelled, a structured mesh was applied to all components. This required minor geometrical simplifications to be made on the transfer and exhaust port geometries which were imported from an IGES file.

Cell skewness and aspect ratio may become a problem when a structured grid is applied to a non-rectangular domain. This problem was noticed when the structured grid was applied to the cylindrical combustion chamber. In order to reduce the skewness, the cylinder was divided into smaller and more rectangular portions. The engine geometry and mesh refinement are illustrated in Figure 2.

Mesh motion - The code enables the user to deform and re-mesh the grid with each successive time step. We used this deforming grid technique to achieve the moving piston, and arbitrary interfaces to connect the deforming cylinder grid with the static port blocks. Arbitrary interfaces allow separate grid blocks to communicate flow without requiring point-to-point grids. This capability makes a sliding grid simulation possible. The maximum spacing between the interfaces was less than $10 \%$ of the last cells length. To minimize the computational error, the deformed grid density of the cylinder was set to approximately align with the grid density used at the arbitrary interfaces of the transfer and exhaust ports. Figure 3 shows the arbitrary interfaces as defined in our modeling.

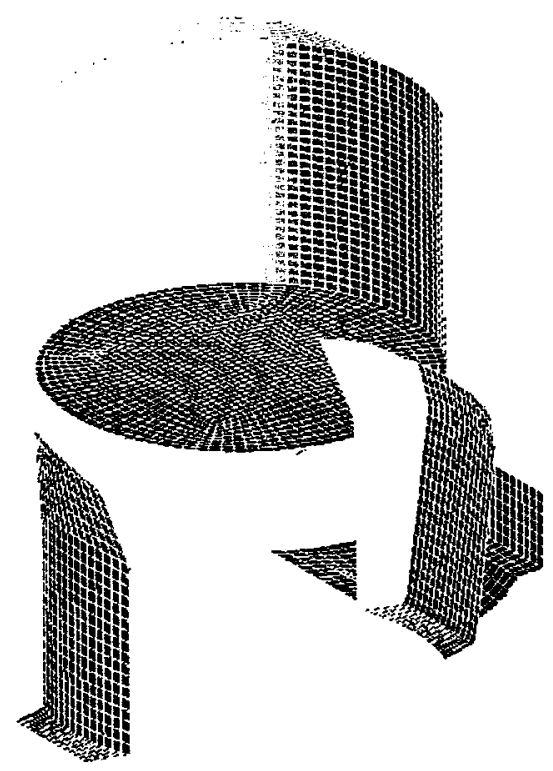

Figure 2 Engine geometry and mesh refinement

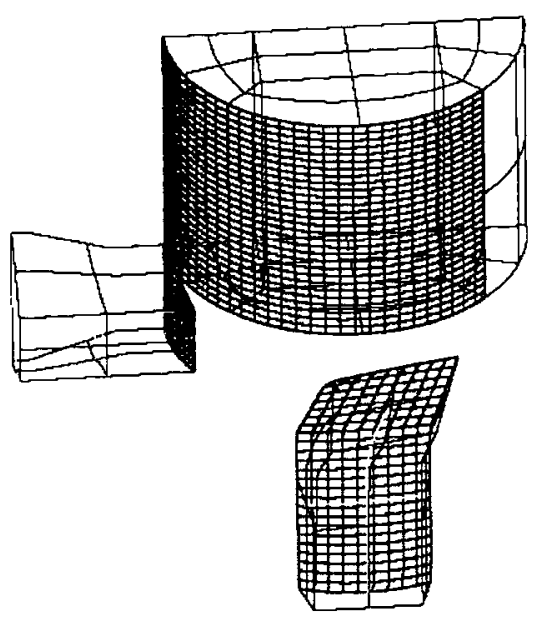

Figure 3 Arbitrary interfaces

Initialization and boundary conditions - The working fluid passing through the engine is compressible air. The simulation starts when the exhaust port opens and ends when the exhaust port closes in one engine cycle. The boundary conditions at the transfer port inlets (interfaces of transfer ports and cylinder) and the exhaust outlet are set by pressure. Experimental data of pressure measured at the transfer port were used to define the 
boundary condition. Previous experience shows that this could greatly reduce the uncertainty of the plug-flow assumption used by other researchers for velocity boundaries at the interfaces of the ports and the cylinder [7].

Solver settings - CFL condition, an important parameter governing the stability of the time dependent model, was used to determine the time step. The general rule is that the time step must be less than the smallest spatial separation in the generated mesh. To ensure that a solution does not overshoot the computational domain, the CFL number must be less than one. This means that a piece of fluid travelling through the computational domain must not travel through the corresponding upwind cell during the period of one time step in the computation. In our computation, 300 time steps were used, equivalent to a time step of $2.350 \mathrm{E}-5$ second for the engine speed of 3000 RPM.

Verification - The model was preliminarily verified by comparing the simulated cylinder pressure with the experimentally measured one. Figure 4 shows the comparison between the two results. Note that the pressure in $\mathrm{kPa}$ is gauge pressure. The cylinder pressure was measured using a $P C B$ pressure transducer. The engine speed is 3000 RPM at full load. The pressure transducer was installed in a side position of the cylinder head. The pressure at the same position from the numerical modeling was extracted for this comparison.

As shown in Figure 4, following the exhaust port opening at $105.86^{\circ}$ ATDC, the pressure in the cylinder begins to blowdown to atmospheric pressure. This occurs over approximately $22^{\circ}$ of crank rotation. The cylinder pressure in the blowdown period has a gradient of approximately $-2.68 \mathrm{kPa}$ per degree of crank rotation. It can also be noticed from Figure 4 that both pressure traces show processes of blowdown, vacuum, introduction of fresh charge, and compression in a cycle. The good agreement between the experimental and numerical results of pressure verifies that the model is reasonably capable of predicting the cylinder pressure characteristics during the blowdown period.

\section{VISUALIZATION OF AIR SHORT-CIRCUITING}

Different visualization methods have been tested. Results for three of them are presented as follows.

SPRAY MODULE - A spay module is provided by CFD$A C E$, mainly for simulating fluid flows with particles sprayed into the fluid. This module was tested as one of the visualization methods for air short-circuiting by injecting particles into the transfer ports and then tracing the particles during the scavenging. We chose this method with an assumption that the number of particles may allow for the estimation of trapping efficiencies.

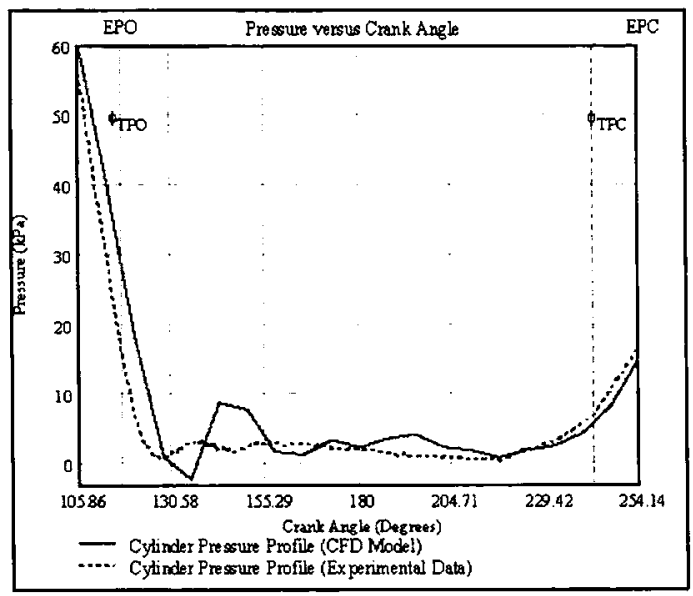

Figure 4 Comparison of the cylinder pressures measured and simulated, at 3000 RPM and full load.

The spray module allows the injection of massless particles into the model. The particles in our simulation were defined as incompressible fluid. As we believed originally, the lack of density and mass of the particle ensured that the injected particles did not disturb the air flow to be simulated in the cylinder, and that inside the computational domain the particles' movement could be easily traceable.

In our simulation, the spray particles mixed in the air (or fresh charge in real), were pulsed into the transfer port on four equally spaced time steps throughout the simulation. The injections occurred at: exhaust port open, $149^{\circ}$ ATDC, BDC, $212^{\circ}$ ATDC. At each of these injection times, 50 random particles were injected into one transfer port, to simulate the fresh charge entering the cylinder via the transfer port. Figure 5 shows the particle distribution at three different times. As shown in Figure $5(a)$, the accumulated sprayed particles are mixed in the fresh charge at the top of the transfer port at the time when the exhaust port opens. By the time the piston reaches $B D C$, as shown in Figure $5(\mathrm{~b})$, approximately 100 particles have been transferred into the cylinder. Some short circuiting can be observed, but the majority of the particles are in the dome at the top of the cylinder. By the time the exhaust port is closing, as shown in Figure 5(c), a significant amount of fresh charge escapes via the exhaust port. Analyzing the stages in between those illustrated above may improve our understanding of the detailed short circuiting process in this particular engine.

The air short-circuiting visualized by the spray module however, differs from that by the other methods reported in the following sections. The short-circuiting noticed in the later stage of the scavenging by the spayed particles occurs much earlier in the modified Janté analysis and the thermal images. This may be due to the control of the spray injection. More experience is required in selecting the timing, frequency, and positions for 


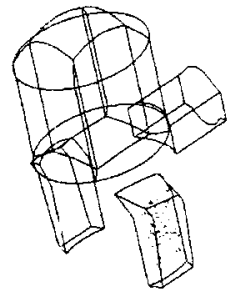

(a)

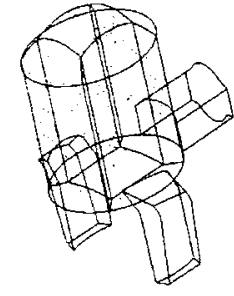

(b)

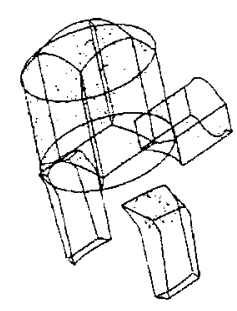

(c)
Figure 5 Visualization of air short-circuiting using particle spay, 2000RPM and full load. (a) Exhaust port open (b) BDC (c) Exhaust port close.

spraying the right number of particles, and defining their drag coefficient in order to use the spray particle method effectively.

The disadvantage of this method is that it proved to be harder than others to implement, due to the complexity of the input.

MODIFIED JANTE ANALYSIS - The Jante method is an experiment-based method to qualitatively identify the 'good' or 'poor' port design of a two-stroke engine. In a Janté test, the cylinder head is removed. A comb of Pitot tubes is installed to measure the axial velocities of the fluid in a plane just above the open cylinder. To simulate this, a radial-cut was made through the cylinder model in close proximity to the cylinder head as shown in Figure 6 . The velocities are displayed using contour plots in accordance with Janté's plots. A general positive velocity on the back wall (opposite the exhaust port), stagnation along the centre line between the back and front wall, and negative velocities on the exhaust port side are expected if good scavenging is occurring.

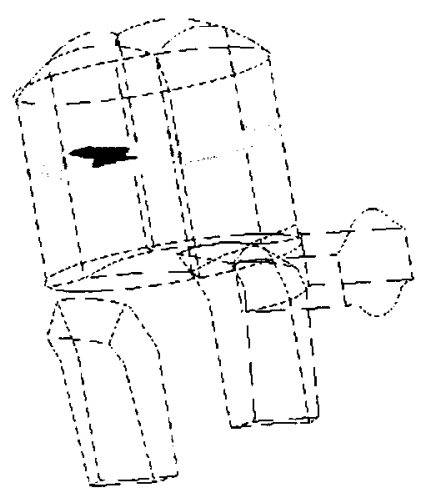

Figure 6 Radial cut position for Janté analysis

Figure $7(a)$ shows the Janté diagram at $150.35^{\circ}$ ATDC As the piston moves downward, the opening of the transfer port increases. The darker (black) color shows the positive or upward velocity, and the lighter (grey) color shows the negative or downward velocity. A small region of positive high velocity in the centre of the cylinder displays as a 'tongue' pattern in Figure 7(a). The flow surrounding the 'tongue', in the lightest grey (green in color print), protruding to the exhaust side of the cylinder indicates negative velocities and a flow toward the exhaust port. In addition to this are regions of negative velocities, forming symmetrically about the high velocity region. Negative velocities are also present on the front and back wall of the cylinder. It is clear from this figure that short circuiting is occurring.

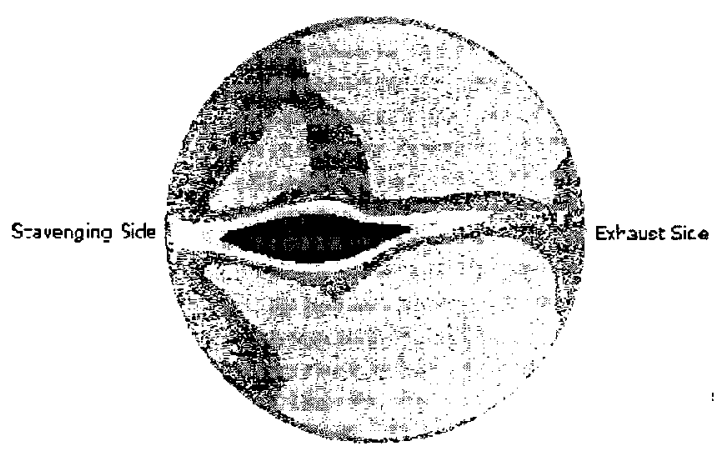

(a) $150.35^{\circ}$ ATDC

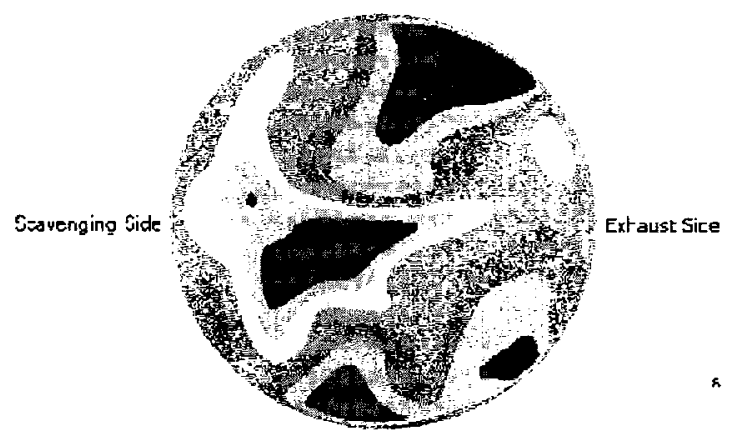

(b) BDC

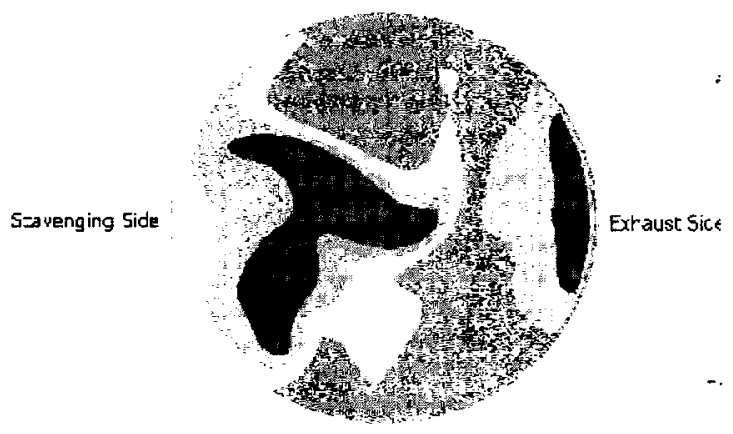

(c) $209.66^{\circ}$ ATDC

Figure 7 Axial velocity contours at on radial planes at different crank angles, at 3000RPM and full load. 
At $\mathrm{BDC}$, the 'tongue' pattern is weakening and the downward velocities have developed directly above each of the transfer ports, as shown in Figure 7(b). This suggests that vortices may have developed above the transfer ports and are swirling the fresh charge in a loop motion perpendicular to the looping motion the blister ports are trying to achieve. This, together with the weakening tongue pattern, indicates mixing occurring between the fresh charge and the combusted gases. As the velocity of the fresh charge entering the cylinder reduces, the formation of an asymmetric pattern occurs.

The velocity of the incoming fresh charge reduces further and the asymmetric pattern significantly develops. Figure 7 (c) shows distinct positive velocities of $60 \mathrm{~m} / \mathrm{s}$ on the back wall and equally negative velocities on the exhaust side. There is still a protruding 'tongue' pattern present and no distinct stagnation line perpendicular to the exhaust port through the centre of the cylinder. However, this pattern may suggest a certain degree of loop scavenging occurring.

The feature shown in all of the images in Figure 7 is the positive (upward) axial velocities predominantly positioned centrally in the cylinder. This indicates that the blister ports are not directing the fresh charge toward the back wall (opposite the exhaust port) of the cylinder. The flow stream entering from the transfer ports is expanding and mixing with the exhaust gas. This fresh charge short-circuiting and mixing with exhaust gas in the earlier scavenging period could be the major causes of high fuel consumption and $\mathrm{HC}$ emission.

THERMAL IMAGES - Thermal images were also used to visualize the air short-circuiting, based on the phenomenon that the fresh charge and the exhaust gas are in two distinguishable temperature ranges. This method may be used to identify the volume and mass of the fresh charge short-circuited through the exhaust port or mixed with the exhaust gas. Figure 8 shows the thermal profiles on an axial-cut plane at the $135.52^{\circ}$ ATDC. As shown in this figure, the region with the lower temperature of approximately $380^{\circ} \mathrm{K} \quad\left(107^{\circ} \mathrm{C}\right)$ is displayed in lighter color at the exit of the transfer port. The fresh charge at lower temperature is surrounded by exhaust, displayed in darker color, at much higher temperature.

Figure $8(b)$ is the thermal image on the same surface as (a) but at a crank angle of $142.93^{\circ}$ ATDC. It shows a large volume of fresh charge, presented in lighter color, is moving toward the back wall of the cylinder. In the wide 'belt' surrounding, significant heat transfer may have occurred by mixing. The temperature in this 'belt' is in the order of $400-500^{\circ} \mathrm{K}\left(127-227^{\circ} \mathrm{C}\right)$. Figure $8(\mathrm{~b})$ also shows that part of the fresh charge flows straight out of the exhaust port. The unavoidable mixing of the exhaust gas and the fresh charge is also apparent. The narrow 'belt' in the lightest color has a temperature around $540^{\circ} \mathrm{K}\left(267^{\circ} \mathrm{C}\right)$ and clearly indicates that this region is occupied by the mixture. The protruding 'nose' at the

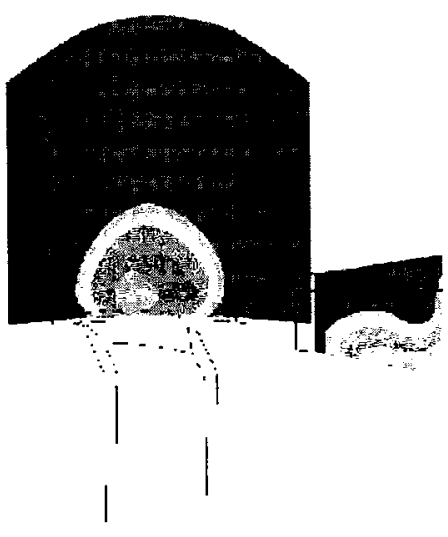

(a) $135.52^{\circ}$ ATDC

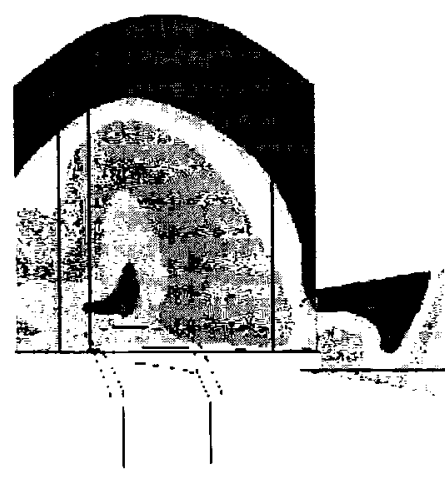

1

(b) $142.93^{\circ}$ ATDC

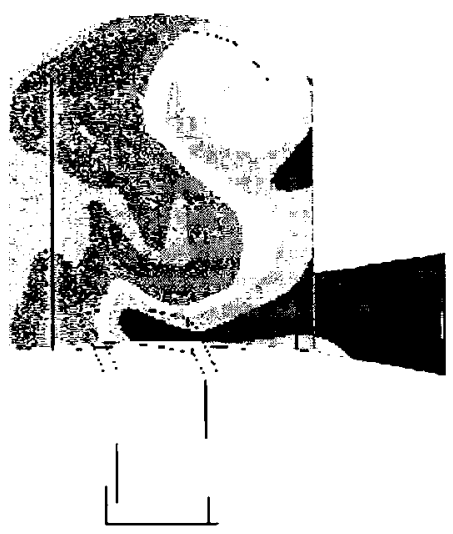

(c) $194.83^{\circ}$ ATDC

Figure 8 Thermal images of axial planes at different crank angles, at 3000RPM and full load. 
interface of the cylinder wall and the exhaust port indicates the fresh charge short-circuiting. At $194.83^{\circ}$ ATDC, as shown in Figure 8(c), the piston is moving upward and the cylinder volume opposite the exhaust port is taken by the fresh charge at lower temperature, driving the rest of the gas towards the exhaust port.

By analysing the thermal images of the fluid in the cylinder, it is clear that the fresh charge short-circuiting does occur in the earlier stage of the scavenging process, and mixing is evident. This supports the earlier findings, from the modified Janté plots, that the fresh charge is not being directed toward the back wall in the early stages of the downward piston stroke. With the gas properties, it is possible to define a threshold of temperature as the transition or mixing of the fresh charge and the exhaust gas. By doing so, the volume and the mass of the fresh charge may be calculated, especially the one short-circuited through the exhaust port.

\section{CONCLUSION}

Three different visualization methods were examined for investigating the air short-circuiting in a small two-stroke engine with a 3-D CFD model.

The spray module may be used to quantitatively identify the air short-circuiting. However, more knowledge and experience are required for defining the properties of the particles properly, including the drag coefficient, and for controlling the spray of the particles.

The Jante analysis using the numerical results of the engine modeling may replace the experiments using a comb of pitot tubes in a steady state flow condition. The similar analysis based on experiments may be modified and applied to finding the quality of a port design. However, the question left from our work is how useful the Jante analysis is when the unsteady flow, rather than steady state, is computationally simulated.

The thermal images may be used to detect the loss of fresh charge short-circuited through the exhaust port. It is possible to extend this method to quantitatively evaluate the loss of the fresh charge, if the fresh charge is not largely mixed with the exhaust gas and in a temperature range distinguishably lower than that of the exhaust gas.

\section{ACKNOWLEDGMENTS}

The reported work is part of a research project carried out at the University of Technology, Sydney. The authors would like to acknowledge the support provided by a UTS Research Grant.

\section{REFERENCES}

1. Celik, I., Yavuz, I. and Smirnov, A., "Large eddy simulations of in-cylinder turbulence for internal combustion engines: a review", Int. J. Engine Research, Vol. 2, No. 2, pp119-148, 2001.

2. Creaven, J.P., Fleck, R., Kenny, R.G. and Cunnungham, G., "Laser Doppler velocimetry measurements of flow within the cylinder of a motored two-stroke cycle engine - comparison with some computational fluid dynamics prediction", Int. J. Engine Res., Vol. 4, No. 2, pp103-128, 2003.

3. Dekanski, C.W., Bloor, M.I.G., Wilson, M.J., "A parametric model of a 2-stroke engine for design and analysis", Comut. Methods Appl. Mech. Engrg., 137 (1996) 411-425.

4. Moriyoshi, Y., Mori, K., Morikawa, K. and Takimoto, $\mathrm{H}$., "Miture formation analysis of a Schnurle-type two-stroke gasoline DI engine", SAE paper 2001-011091, 2001.

5. Raghunathan, B.D. and Kenny, R.G., "CFD simulation and validation of the flow within a motored two-stroke engine", SAE paper 970359, 1997.

6. Sukegawa, Y., Nogi, T. and Kihara, Y., "In-cylinder airflow of automotive engine by quasi-direct numerical simulation", JSAE Review 24 (2003) 123126.

7. Yu, L., Campbell, T. and Pollock, W., "A simulation model for direct-fuel-injection of two-stroke gasoline engines", SAE paper 970366, 1997. 